\title{
Building Communication Awareness for the Next Generation: Reviewing the Factors Inhibiting Youth Entrepreneurial Activity in Korea
}

\author{
Ty Choi, Reid McLain
}

Hankuk University of Foreign Studies, Yongin, Korea

Objectives: While Korea is known to be entrepreneurial and the country is known to be driven by an innovative economy, entrepreneurial activity is more apparent within established businesses but not so much with new business ventures established by the youth and through education. This study will attempt to draw out the inherent factors, including those relating to business communication, which lead to the low propensity for youth entrepreneurship in Korea and determine the sources/causes of those factors.

Methods: To identify and determine the sources of the factors, we reviewed and adapted literature for the traits, motivations, and barriers of entrepreneurs and entrepreneurship. We then surveyed articles providing case data of Korean youth to testify to those three aspects of entrepreneurs.

Results: We ascertained that Korean youth lacked entrepreneurial activities and showed a low propensity to consider entrepreneurship a career path. This does not mean that Korean youth lack the capabilities to become entrepreneurs. Still, through the established cultural communication norms, they lack the self-awareness, exposure, experiences, and education for them to want to pursue entrepreneurship.

Conclusions: From this study, we identified several factors and possible sources that reveal why Korean youth entrepreneurship is lacking. Our conceptual model specifies eight enablers that serve as guidelines and identify some communication norms that may need to be adjusted to help key players encourage entrepreneurial activity in youth.

Key Words: Early-Stage Entrepreneurship, Korean Youth, Entrepreneurship Education, 8 Enablers of Entrepreneurship, Cultural Norms

Received: May 23, 2021 Revised: Jun 17, 2021 Accepted: Jun 30, 2021 Corresponding author: Ty Choi

Hankuk University of Foreign Studies, Global Campus, 81, Oedae-ro, Mohyeon-eup, Cheoin-gu, Yongin-si, Gyeonggi-do, 17035, Korea

Tel: +82-31-330-4585, E-mail: tyc@hufs.ac.kr

This is an Open Access article distributed under the terms of the Creative Commons Attribution Non-Commercial License (http://creativecommons.org/licenses/ by-nc/4.0/) which permits unrestricted non-commercial use, distribution, and reproduction in any medium, provided the original work is properly cited.

Copyright $\odot 2021$ Korean Association for Business Communication.

\section{Introduction}

As South Korea (hereafter 'Korea') shifts to a more knowledge-work economy, the need to prepare new workers to understand these entrepreneurial business communication dynamics has become more valuable than in years past. Because of this, educational goals should include the encouragement and implementation of entrepreneurial education before workers reach the workforce. To understand why it is important to establish the current scenario of entrepreneurial education and see how Korea measures with other countries. 
According to the Global Entrepreneurship Monitor 2020/2021 ('GEM 20/21') report (Bosma et al., 2021), out of a total of 43 participant countries around the world, Korea was placed 30th for 'Total early-stage Entrepreneurial Activity (TEA)' level with only $7.1 \%$ of respondents in the age group between 18 to 24 having some experience with entrepreneurial activities. Comparing this to other countries such as Angola (54.2\%: 1st), US (15.1\%: 19th), UAE (18.4\%: 15th), and Colombia (33.1\%: 4th), we may start questioning as to why Korea is so low. There are advanced nations with lower levels of youth entrepreneurship than Korea. Countries such as Germany (6.8\%: 32nd), Italy (3.6\%: 41st), and Spain (4.5\%: 39th) being lower than Korea may indicate that the original number and ranking are acceptable.

However, a similar disparity in outcome for Korea was shown in a report from Guelich and Bosma (2019), which studied youth entrepreneurship of nine countries in the Asia Pacific. The report showed that Korea was the second to last among nine neighboring countries, with only $3.6 \%$ of youth aged between 18 to 34 having been involved in entrepreneurial activities. The highest figure was from Indonesia with $18.9 \%$. With the exception of Malaysia, which came last behind Korea with $2.8 \%$, every other country in the region reported over 10\%, showing noticeable parity between Korea and the rest of the area. By no means do these figures prove that entrepreneurial activities are lacking in Korea as a nation, but rather that the activities are reserved for later in life and absent with the youth. According to the GEM 20/21 (2021), Korea came 2nd among the 43 nations with $16.1 \%$ of all adults involved in entrepreneurial activities within the established business, which are generally referred to as 'intrapreneurship' or 'corporate entrepreneurship'.

This background points us to our question: While the country is somewhat known to be entrepreneurial and the country is known to be driven by an innovative economy, why is an entrepreneurial activity more apparent within the established businesses but not so much with new business ventures established by the youth and through education? Perhaps a few reasons such as the risk adversity level of Korean youth, the lack of creativity, the focus on standardized testing, the perception towards Chaebol (Korean large conglomerate companies) employment as a success indicator (Hultberg et al., 2021), the lack of exposure to entrepreneurial experiences, and the lack of entrepreneurship education (Yoon, Donthu, \& Lenartowicz, 2021) could offer some perspectives to the causes. Therefore, this study will attempt to draw out factors leading to the low propensity for youth entrepreneurship in Korea and to determine the sources/causes of those factors.

\section{Framework of the Study}

\section{Is Entrepreneurial Education Lacking in Korea?}

As shown in the GEM 20/21 (2021), Korea shows some noticeable disparity in entrepreneurial framework conditions as shown below in Table 1. We found that Korea has many high-ranking attributes for entrepreneurial framework conditions, but also ranks low in other attributes. While macro-environmental factors such as ease of entry, market dynamics, government policy, access to entrepreneurial finance, and physical infrastructures are found to be advanced, factors more relevant to entrepreneurs (micro factors) are shown to be somewhat lacking. By no means does this assessment show reason for serious concern, as the majority of factors are either on median position (ranks: 18/45-22/45) or just off the first quadrant (ranks: $12 / 45-13 / 45)$, meaning Korea is doing relatively well across all factors.

This assessment leads us to question why micro factors that are tied to the entrepreneurial activities of individual entrepreneurs are somewhat lacking. Despite the high level of government policy promoting entrepreneurship hence well-advanced infrastructures for entrepreneurial activities are possible, lower levels of social and cultural norms and entrepreneurial education could be the contributing factors of lower-level participation in entrepreneurial activities. What we have been able to identify is that the overall participation in entrepreneurial

Table 1. Expert ratings of Korea's entrepreneurial framework conditions

\begin{tabular}{lcc}
\hline Entrepreneurial framework conditions & Ratings & $\begin{array}{c}\text { Rank } \\
\text { (out of 45) }\end{array}$ \\
\hline Social and cultural norms & 5.2 & 18 \\
Access to entrepreneurial finance & 5.6 & 8 \\
Government policy: support and relevance & 6.2 & 5 \\
Government policy: taxes and bureaucracy & 5.1 & 12 \\
Government entrepreneurship programs & 5.8 & 13 \\
Entrepreneurial education at school & 3.9 & 12 \\
Entrepreneurial education at post-school & 4.6 & 22 \\
Research and development transfer & 4.5 & 18 \\
Commercial and professional infrastructure & 4.8 & 29 \\
Ease of entry: market dynamics & 7.9 & 1 \\
Ease of entry: market burdens and regulations & 4.5 & 21 \\
Physical infrastructure & 7.8 & 6 \\
\hline
\end{tabular}

Note. Rating $0=$ very inadequate insufficient status, $10=$ very adequate sufficient status.

Adapted from "2020/2021 global report," by Bosma et al., 2021. Copyright 2021 by Global Entrepreneurship Research Association. Reprinted with permission. 
activities is not equal across all age groups. We found that the lower participation level from younger generations (age 18-34) significantly drags down the overall level for the country. The following table shows the significant disparity between younger and older generations (Table 2) .

\section{Specific Research Questions and Entrepreneurial Framework}

In addition to the overall research question we have already stated, we pose more specific questions as follows;

- RQ1: Does Korea need to worry about the youth in regards to entrepreneurial education?

- RQ2: Would increasing the numbers amongst the younger demographics help Korea's overall entrepreneurial environment?

For us to be able to draw out some perspectives on the above questions, we believe it is important to understand interrelationships between traits, motivations, and barriers of entrepreneurs that are driving factors for individuals to participate in entrepreneurship. Then create a framework to guide areas that may need to be looked at to gauge out how Korea can encourage more youth to participate in entrepreneurial activities.

A recent article by Yoon (2021) indicates that there may be a rising demand for entrepreneurship to be a choice in Korean education. He questions whether the Korean education system is entrepreneur-ready and advocates some changes to the

Table 2. Korea's profile of total early-stage entrepreneurial activity (TEA)

\begin{tabular}{lcc}
\hline Age group & $\begin{array}{c}\text { Score } \\
\text { (\% of age group) }\end{array}$ & $\begin{array}{c}\text { Rank } \\
\text { (out of number indicated in brackets) }\end{array}$ \\
\hline $18-24$ & 7.1 & $30(43)$ \\
$25-34$ & 12.4 & $24(43)$ \\
$35-44$ & 16.4 & $15(39)$ \\
$45-54$ & 13.0 & $15(39)$ \\
$55-64$ & 13.5 & $12(39)$ \\
\hline
\end{tabular}

Note. Adapted from “2020/2021 global report," by Bosma et al., 2021. Copyright 2021 by Global Entrepreneurship Research Association. Reprinted with permission. norms of the education system to facilitate this. We linked his suggestions with underperforming attributes of entrepreneurial framework conditions we discussed above to display their relevance (Table 3 ) .

\section{Traits, Motivations, and Barriers of Entrepreneurs}

In this section, we study traits, motivations, and barriers of entrepreneurs and see how Korean culture aligns with these to identify its strengths and weaknesses and create a framework to understand what needs to be changed.

\section{Traits of Entrepreneurs}

There are many studies questioning whether entrepreneurs are born or raised, the idea of nature vs nurture. Specifically, these studies spell out traits that are commonly possessed by entrepreneurs. The importance of studying these traits comes in two folds that are relevant to this study. First, we need to understand whether Korean youth possess such traits in general. We recognize that it is impossible to stereotype Korean youth to the traits identified in many studies; however, assessment and identification of likeliness of stereotypical Korean youth's propensity for possessing entrepreneurial traits or not will lead to possible indications as reasons for lack in Korean youth entrepreneurship. Second, we can assess current Korean education systems to see whether the current systems are capable of developing such traits. Of many measures of entrepreneurial traits, we adapted Amiri and Marimaei (2012), Driessen and Zwart (2017) and Kerr, Kerr, and $\mathrm{Xu}$ (2017) to construct the following diagram (Figure 1).

As can be seen from the following chart in Figure 2, 32.1\% of the Ulsan University students who participated indicated 'Job Stability' as the highest criterion for a job selection, which may indicate a low level of risk tolerance. As is shown in Figure 1, entrepreneurs possess a high level of risk tolerance and a higher propensity to risk. It is widely accepted that entrepreneurship is inherently riskier than getting employed in established businesses.

Table 3. Linking areas requiring changes to entrepreneurial framework conditions

\begin{tabular}{|c|c|}
\hline Required changes (Yoon, 2021) & Linking to entrepreneurial framework conditions (Bosma et al., 2021) \\
\hline Conflicts between standardized testing vs creativity and innovation & Education systems \\
\hline Change the focus on admission to high-level universities & Education systems \& Social and cultural norms \\
\hline $\begin{array}{l}\text { Change job focus from those with Korean conglomerates and } \\
\text { government jobs to other options }\end{array}$ & Education systems \& Social and cultural norms \\
\hline
\end{tabular}




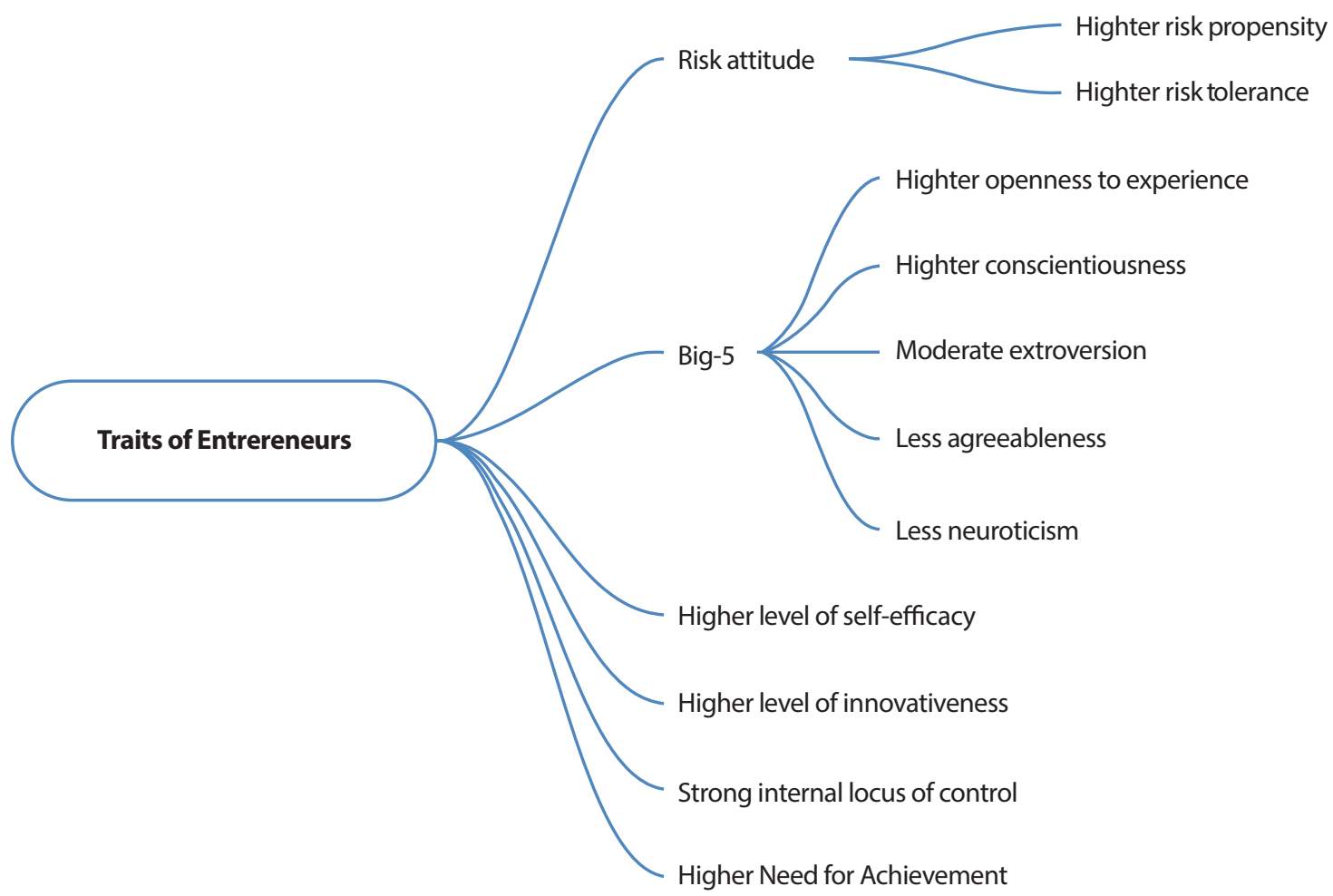

Figure 1. Traits of entrepreneurs. Adapted from “Concept of entrepreneurship and entrepreneurs traits and characteristics," by Amiri \& Marimaei, 2012. Copyright 2012 by Scholarly Journals International. Adapted from "Personality traits of entrepreneurs: A review of recent literature," by Kerr et al., 2017. Copyright 2017 by authors. Adapted from “The entrepreneur scan measuring characteristics and traits of entrepreneurs," by Driessen \& Zwart, 2017. Copyright 2017 by authors.

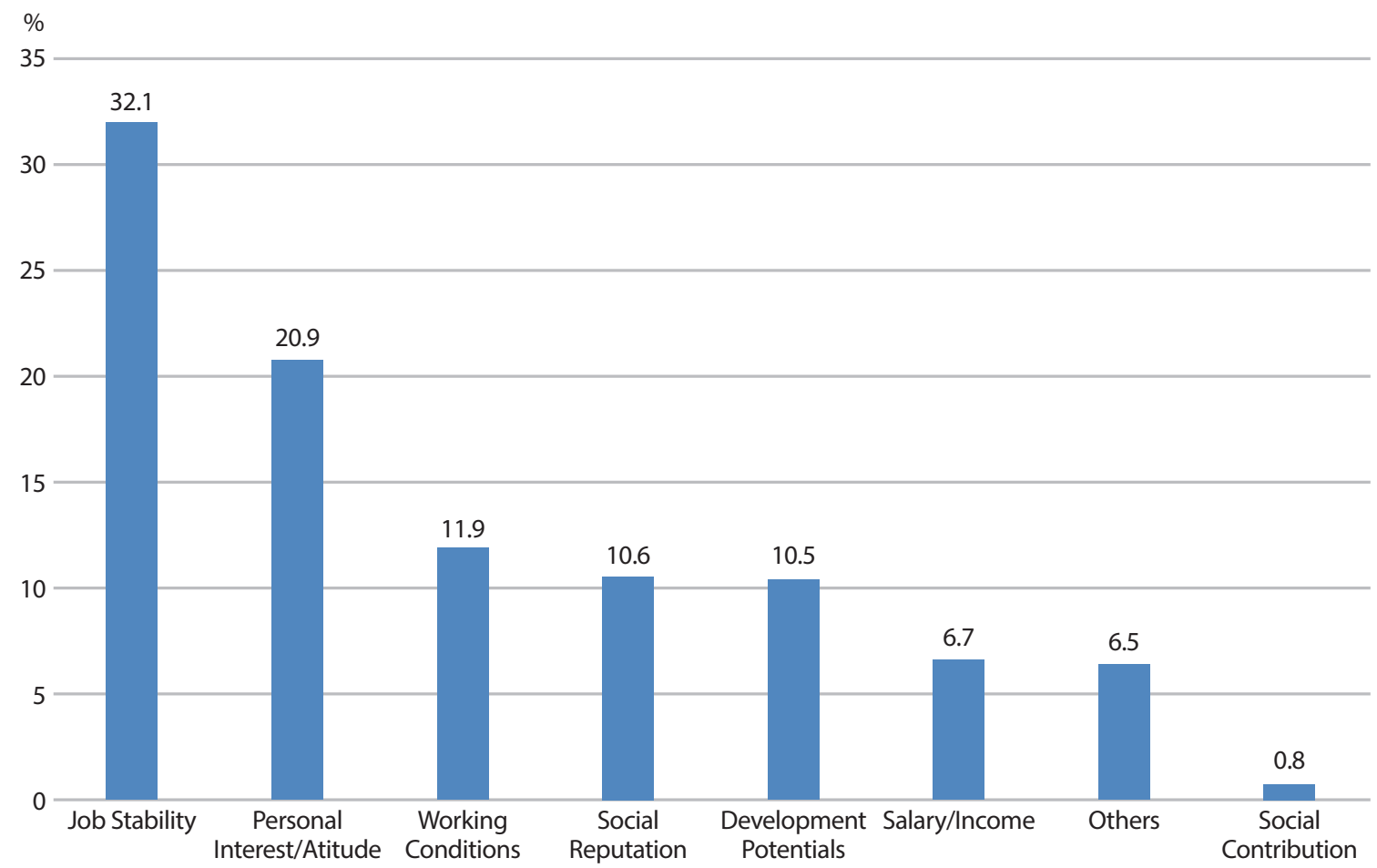

Figure 2. Most important factors when choosing a job (survey participants from Ulsan university). Adapted from "What are the criteria for choosing a job for college students," by Park, 2020. Copyright 2020 by University of Ulsan. Reprinted with permission. 
Another indicator shown below in Figure 3 also shows a similar factor displayed by Korean youth of risk adversity as discussed above.

$68.1 \%$ of the respondents chose 'getting employed' as their preference, as opposed to $5.1 \%$ for 'start-up (entrepreneurial activity), supporting the consistency of the lower level of Korean youth entrepreneurship.

Looking closer into types of employment preferred by the students further indicates their propensity to 'job stability as a majority of respondents preferred to be employed in either large corporations (26.6\%), public enterprises (18.1\%) or public sector (11\%) opposed to medium-sized corporations (11\%) or small-to-medium sized enterprises (5.3\%). Such skewed preferences for employment in large corporations and public sectors indicate their preference for the perceived job stability but is also a reflection of social and cultural norms of what 'success' means for Korean youth. While the vast majority of Korean youth aspire to have a flourishing career in perceptually stable employment as discussed, the reality shows an alarming issue. According to research conducted by the Ministry of Education (MoE) in 2020, only $10.9 \%$ of higher education graduates were employed by large corporations, $8.2 \%$ in public institutions/ enterprises, and 6.1\% became public servants (Ministry of Education, 2020). The majority (46\%) were employed in small to

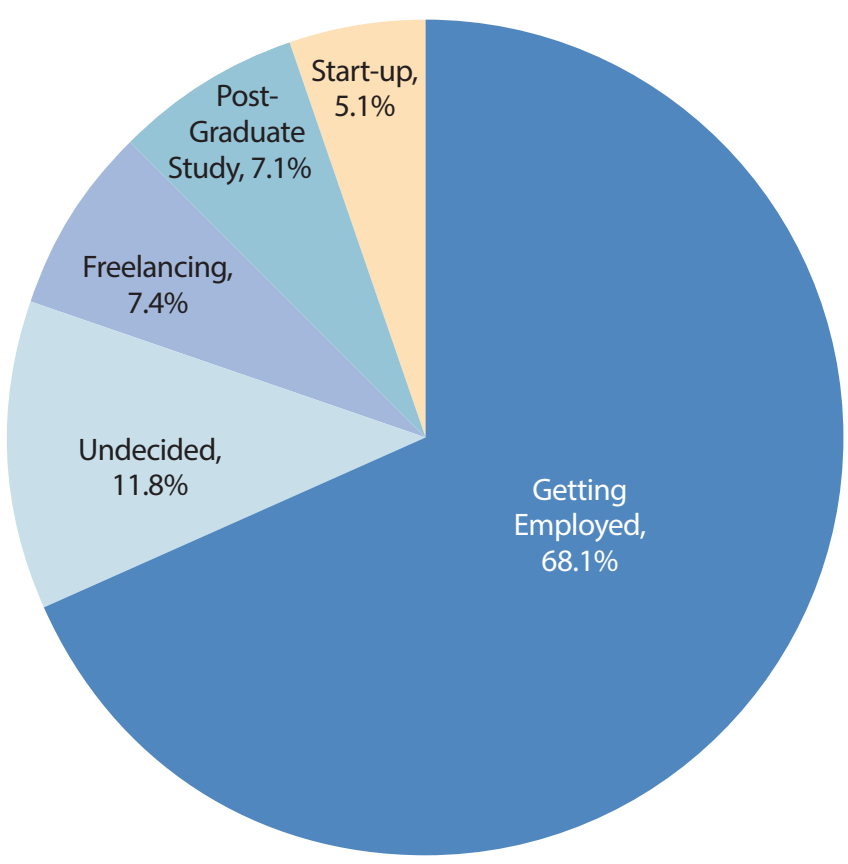

Figure 3. Career aspirations after graduation (survey participants from Ulsan university). Adapted from "What are the criteria for choosing a job for college students," by Park, 2020. Copyright 2020 by University of Ulsan. Reprinted with permission. medium enterprises (SMEs), clearly indicating a significant discrepancy between Korean youth's preferred aspirations to actual results. This creates social problems, which have consequences with which Korean people are already familiar. High levels of youth unemployment and the emergence of NEET ${ }^{1} s$ are the face of those issues.

According to Hwang (2020), a survey conducted by JobsKorea and Albamon in 2020 showed that $46.9 \%$ of university students have no career planning. This may be caused by discouraged youth knowing the facts discussed above of the discrepancies between their ideals and reality. However, what seems to be an indication of a lack of direction (en route) for their own future indicates a lower level of self-efficacy, a weaker internal locus of control, and a lower need for achievement, which are directly opposite traits to what entrepreneurs possess. This brings us to our motive for the study recognizing that a lack of Korean youth entrepreneurship is not only because of a lack of entrepreneurial traits that Korean youth seem to be missing but Korean youth may be victims of external environmental factors that Korean society has supported.

\section{Entrepreneurship Motives}

Alongside distinctive traits of entrepreneurs, many studies claim that strong motivations for success are common to many entrepreneurs, and these motivations are depicted in Figure 4. Therefore, we reviewed several studies in entrepreneurship motives then adapted Giacomin et al. (2011) to construct the following diagram (Figure 4).

There is no doubt that these motives are different among different entrepreneurs, though many will agree that there are high correlations between these motives and personality traits we discussed previously. It is not our intention to debate how motives are created for individuals; however, we believe that both internal and external factors contribute to the creation/recognition of these motives. Hence we wish to put forward a question of whether Korean youth have been either actively/passively exposed to these motives. We need to recognize that exposure to these motives can come in two ways. Active exposure can be expressed as a self-exposure that is driven by one's own willingness, whereas passive exposure may be either parental, educational, and/or societal factors. It will be a 'chicken or the egg' type of question of whether active or passive exposure instigates entrepreneurial motives. Rather than discussing which came first, it is important to recognize that both exposures apart from entrepreneurial education seem lacking for Korean youth according to the studies we have reviewed so far (Han \& Kim, 2013; Kong \& Kim, 2018; Oh \& Park, 2014; Yang, 2015).

\footnotetext{
${ }^{1}$ An acronym for "Not in Education, Employment, or Training".
} 


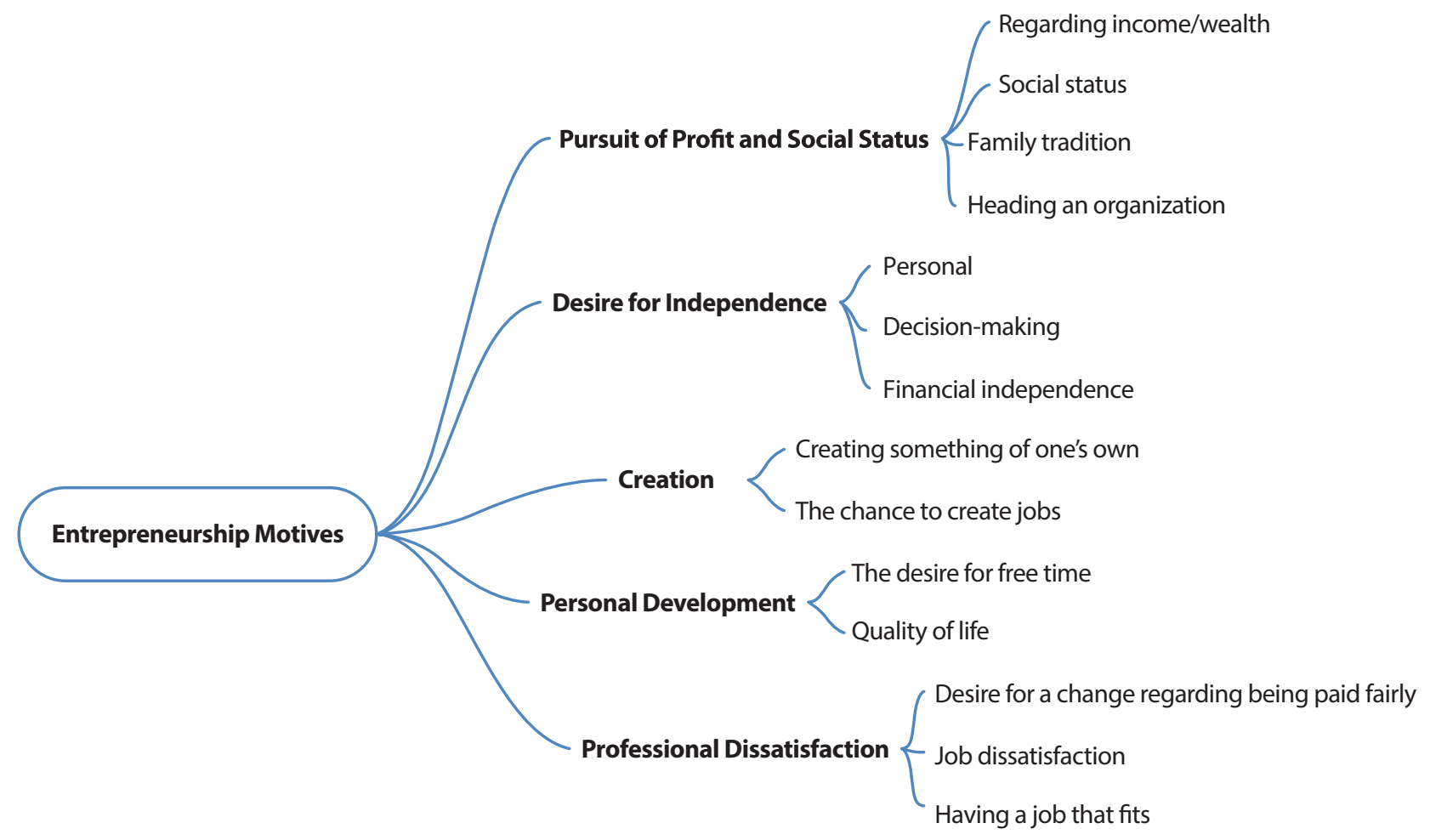

Figure 4. Entrepreneurship motives. Adapted from "Entrepreneurial intentions, motivations and barriers: Differences among American, Asian and European students," by Giacomin et al., 2011. Copyright 2011 by Springer Nature.

\section{Entrepreneurship Barriers}

From what we have identified by studying the relationship between entrepreneurs' traits and motives and also how those explain the causes of a lack of entrepreneurial activities that Korean youth display leads us to study entrepreneurship barriers. The following diagram depicts what we have adapted from Giacomin et al. (2011) of factors that are barriers for entrepreneurs wishing to be involved in entrepreneurial activities.

Similar to the entrepreneurship motives, there are both micro (personal) and macro (external) factors that sway entrepreneurs to deter their entrepreneurial activities. Of what is depicted in Figure 5, a lack of knowledge/experience, a lack of self-confidence, and risk aversion are personal factors that are displayed by Korean youth. There is no doubt that motives and barriers co-exist for all entrepreneurs, however, those who proceed must have their motives outweigh their barriers, meaning propensity to conduct entrepreneurial activities can be driven by those two factors. The possible scenarios to explain the lack of entrepreneurial activities displayed by Korean youth may be explained under the assumption that Korean youth recognize more barriers than the perceived positive outcomes (motives) or complete absence of other factors. We have thus far emphasized the importance of external factors that can impact the internal ones. We do not think that many will question the dil- igence and intellectual capabilities of Korean youth. Hence we draw more of our attention towards external factors such as education, exposure, encouragement, and endorsements that can impact Korean youth internal factors (Lee \& Yang, 2020). We therefore look into building a conceptual model which captures both internal and external factors explaining the current status of Korean youth entrepreneurship.

\section{Discussion}

\section{Conceptual Model for Youth/Early-stage Entrepreneurship}

(a.k.a. 8Es: 8 Enablers of Early-stage Entrepreneurship)

Using the information from the traits and characteristics of entrepreneurs and the data about the current conditions towards people's attitudes towards uncertainty and other cultural communication attributes, we have developed a conceptual model for understanding the different areas of focus that need to be addressed to encourage youth entrepreneurship in Korea. These areas fall into two categories that indicate factors that may influence the internal and external locus of control, as discussed earlier. Internal factors include experience, ego, and enthusiasm; external factors include exposure, endorsement, and encouragement. The main factors of Education and En Route span both areas-internal and external-and can be used to explain the 


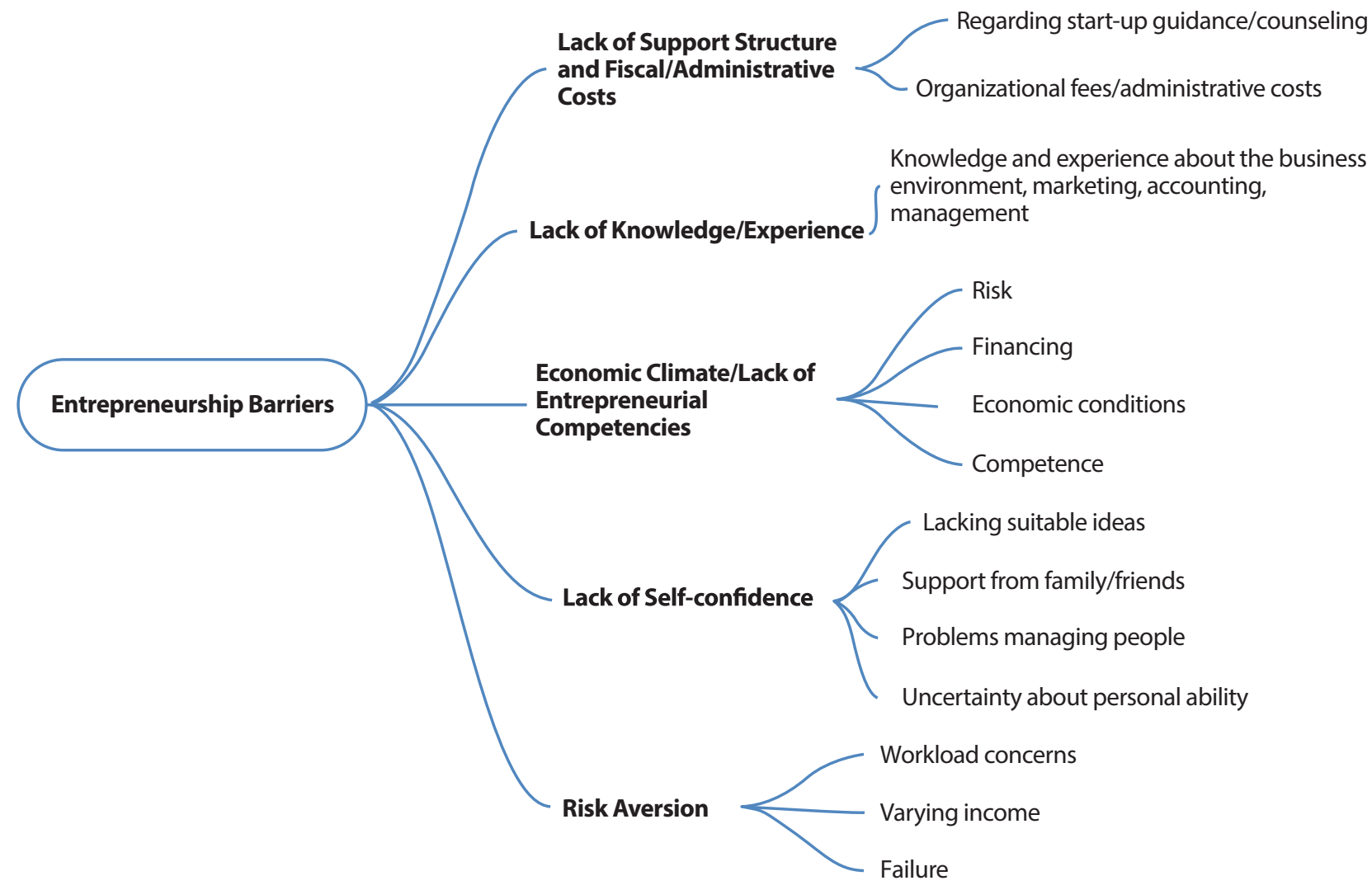

Figure 5. Entrepreneurship barriers. Adapted from “Entrepreneurial intentions, motivations and barriers: Differences among American, Asian and European students," by Giacomin et al., 2011. Copyright 2011 by Springer Nature.

learning environment and career direction. The framework in its current form uses the following definitions as a brief explanation of each of the deficiencies that can help guide the framework for understanding how it can be applied to scenarios.

- Education: The learning and background that sets up the next seven attributes in the framework.

- Experience: Internal factors that influence career decisions.

- Ego: Sense of self in relation to the work environment. Possession of self-driven energy.

- Enthusiasm: Energy as a result of the career choice and work environment.

- Exposure: External factors that influence career decisions. Opportunities available to youth.

- Endorsement: Approval by others. Tangible and infrastructural supports. Government policies.

- Encouragement: External motivation for decision-making and choices. Societal and parental.

- En Route: This is the career direction that is chosen by a job seeker after the other seven attributes are considered (Figure 6).

Using these eight attributes, we can look at scenarios and compare the status quo of what may constitute a deficiency with entrepreneurial encouragement and see how the excep- tions may have done things differently, or the environment may change to help encourage the positive experience by choosing something different than what is expected.

\section{A Need for Cultural Paradigm Shift}

In order to understand the attributes of the eight deficiencies conceptual model for areas to look at when considering adjustments to the norm by encouraging a culture of entrepreneurship, we can use an example of a Yonsei University graduate who changed career paths to become a successful wallpaper installer (Moon, 2021). This example shows where this particular student may have experienced a career path different than what was expected by going to such a prestigious university. In Table 4 , the deficiencies column represents the barriers that would have prevented the job seeker from choosing a different career path (En Route). The culture shift side of the table shows the contrasting environment both with an internal and external locus of control that helped encourage the different En Route for this particular job seeker (Table 4).

Something to note about this situation is that the educational aspect for this particular job seeker did not change until the worker was already in the workforce. The fact that such a story 


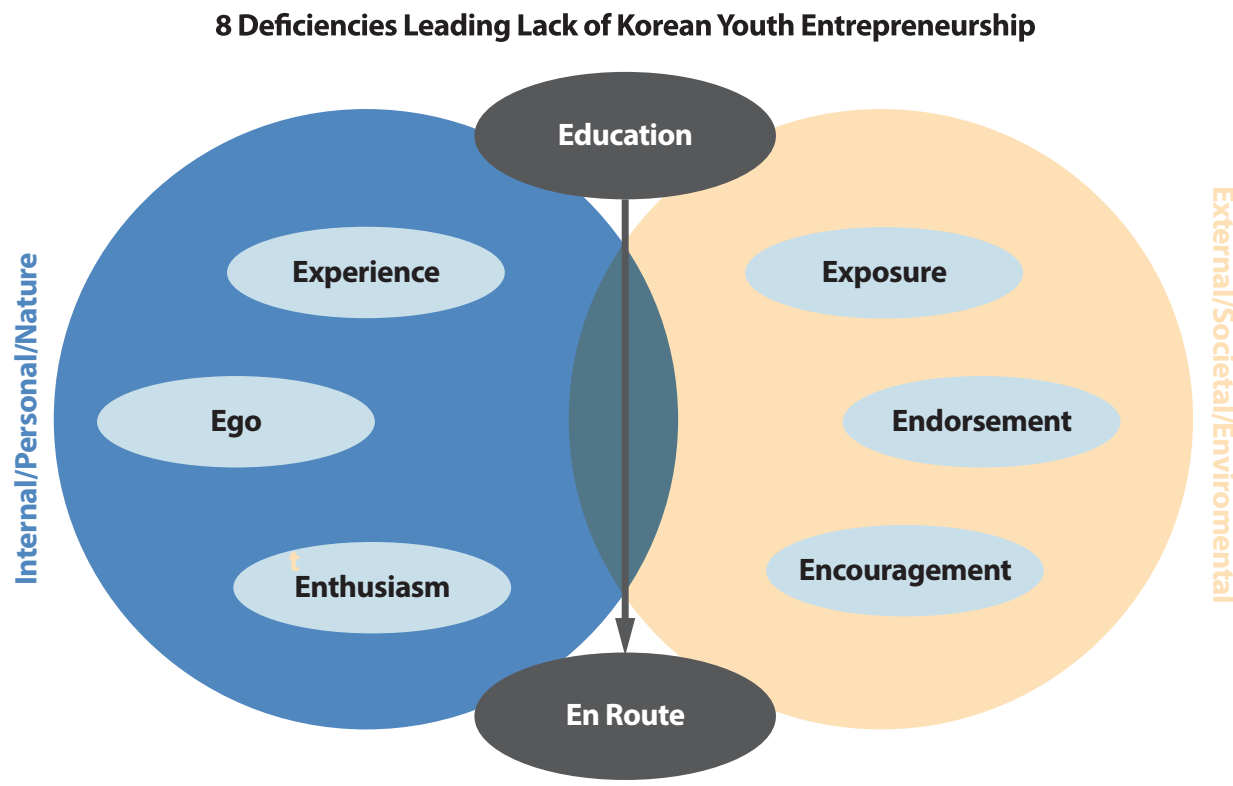

Figure 6. Authors' conceptual model for youth entrepreneurship deficiencies (a.k.a. 8Es: 8 enablers of early-stage entrepreneurship). Source: Developed by the authors.

Table 4. Cultural paradigm shift: Yonsei graduate case

\begin{tabular}{|c|c|c|}
\hline Attribute (8Es) & Deficiencies & Culture shift \\
\hline Education & Archived a perceived high level of educational achievement & No shift - shift happened after graduation \\
\hline Experience & Unhappy and frustrated with current job experience & Found freedom in work \\
\hline Ego & Ego lost in the hierarchy at work & Autonomy at an earlier age \\
\hline Enthusiasm & Low enthusiasm for work and life & High enthusiasm for work and life \\
\hline Exposure & $\begin{array}{l}\text { Negative factors relating to hierarchical and complacent } \\
\text { organizational culture }\end{array}$ & Breakaway from stereotypical paths \\
\hline Endorsement & $\begin{array}{l}\text { Pressure to secure a stable employment in a reputable } \\
\text { organization }\end{array}$ & $\begin{array}{l}\text { Parent's approval to quit the first job and the endorsement } \\
\text { to pursue a career path that is fulfilling personal } \\
\text { satisfaction }\end{array}$ \\
\hline Encouragement & $\begin{array}{l}\text { Wallpaper installer, not a job encouraged based on } \\
\text { educational level }\end{array}$ & $\begin{array}{l}\text { Parents and friends were encouraging for the alternative } \\
\text { route of career path }\end{array}$ \\
\hline En Route & Long process to work up the hierarchy in a traditional job & $\begin{array}{l}\text { Earlier success - book deal, life satisfaction and personal } \\
\text { development }\end{array}$ \\
\hline
\end{tabular}

Note. Deficiencies are interpretative assertions of the authors based on factual information from Moon (2021). Adapted from "Why did a 20s female SKY university graduate become a wall-paper installer? ," by Moon et al., 2021. Copyright 2021 by Kyunghyang Newspaper. Reprinted with permission.

draws public attention for a journalist to write about reflects the current stigma of perceived success paths of Korean youth (i.e., Selective High School-SKY/Reputable University-Conglomerate/Public Sectors). So the framework attributes need to be applied in more cases to find the patterns that may help change this.

Various researchers have studied how culture and entrepreneurial communication norms influence entrepreneurship over the past five decades. Of the many articles in this domain, we reviewed studies that explored how various cultural variables relate to entrepreneurial behaviors and outcomes (Hayton et al., 2002). Ironic as it may sound, Jakubczak and Rakowska (2014) identified that more developed nations reveal low entrepreneurial activities despite the existence of more favorable conditions that should exist for entrepreneurs. They explain that developed nations may contain more stable employment opportunities; hence, taking risks in entrepreneurship is less appealing. This may sound convincing in other developed countries; however, 
with a record of $27.9 \%$ de facto (or extended-based) jobless rate $^{2}$ reported in January 2021 in the 15-29 age group (Kim, 2021), the case of Korean youth may not support Jakubczak and Rakowska's assertion. As we have discussed previously, there is a clear discrepancy between the career aspirations of Korean youth and how much of those aspirations become realities. We suspect that hardly any one of that $27.9 \%$ would consider or ever have considered getting involved in entrepreneurial activities. Our suspicion is not speculative, as Statistics Korea reporting over $62.3 \%$ of unmarried children aged between 22 to 40 are living with parents (the so-called kangaroo tribe ${ }^{3}$ ) and $42.1 \%$ of them are NEETs (Yonhap News, 2021) may support our claim to be valid.

The final factor to consider for the paradigm shift is the structure of the communication environment and the freedom with which younger entrepreneurs can express their ideas. While Hofstede, Hofstede, and Minkov (2010) hinted that low uncertainty avoidance and high masculinity of Hofstede's cultural dimensions would create a good cultural and business communication background for entrepreneurship. With 39 points for masculinity (hence more feminine) and 85 points for uncertainty avoidance (one of the highest countries reported) scores for Korea (Hofstede, 1985), it seems Korea's own cultural dimensions offer some explanations for the low entrepreneurial activity numbers. However, we argue that the low entrepreneurial activities experienced by Korean youth may be shifted by focusing on the individual's needs rather than relying on a survey of the culture at large. This aligns with Jakubczak and Rakowska's (2014) findings whose study found the inapplicability of Hofstede's dimensions to measure the values of individuals. To overcome this, Yoo et al. (2011) developed CVSCALE -a tool for measuring Hofstede values scales at an individual level. This tool has been tested and validated in such countries as the USA, Brazil, Poland, Korea, and Thailand (Prasongsukarn, 2009). Jakubczak \& Rakowska (2014) conducted their own test using CVSCALE. They confirmed that "high masculinity and low uncertainty avoidance are correlated with a better perception of own skills and knowledge needed to become entrepreneurs who are responsible for the individual perception of entrepreneurship readiness." From this study, we suspect that Korean youth may lack the individual perceptions of entrepreneurship readiness because they lack the perception of their own skills and knowledge and ability to communicate those skills with confidence. Furthermore, Choi (2011) found that the demo-

\footnotetext{
${ }^{2}$ Jobless rate is based on the number of unemployed and underemployed in the economically active population.

${ }^{3}$ Kangaroo tribe refers to people who depend on their parents financially and emotionally even as they become old enough to leave the nest (Yonhap News, 2021).
}

cratic parents who respect their child's own decision on his/her own career path have a positive effect on the entrepreneurial intentions of college students. This implies where the power distance dimension of Hofstede in Korea is above average shows how parents' authority can impact the motives of Korean youth entrepreneurship. As was stipulated in Hultberg et al. (2021), Korean parents play a major role in influencing the career paths of their children throughout their school years including the choice of a university and the choice of their university major. In order to confront this issue and turn it around, we once again highlight the importance of entrepreneurial education and changes in communication and social norms. Consequently, the Korean youth can be more exposed to recognizing their own capabilities through our eight enablers of Korean youth entrepreneurship as presented in this paper.

\section{Conclusion}

The results of this study are exploratory. Many questions still remain and new ones need to be pursued. The conceptual framework model based on the ideas present here still needs to be tested. At the beginning of this study, we asked two questions.

The first question was: Does Korea need to worry about its youth in regards to entrepreneurial education? Based on our conceptual model, Korea should take a look at youth entrepreneurial education. Based on the data from the references found in this presentation, we know that the desirable jobs are available to only $10 \%$ of graduates. Encouraging entrepreneurial education may help create new En Routes and career paths for job seekers in Korea. We also highlighted cultural and societal norms of what determines so-called 'success' for Korean youth. Before we start blaming Korean youth as individuals who are entrepreneurially challenged, we must educate our parents, society, and Korean youth that there are other avenues that can indicate a successful life other than getting employed in big conglomerates or in the public sector.

The second question was: Would increasing the numbers amongst the younger demographics help Korea's overall entrepreneurial environment? This question elicits a similar response, as the first. We believe that the answer is yes, but we will not be certain until we try. What we are sure of, however, is that making external factors complete will not be detrimental to Korea regardless of whether or not it will result in a greater number of Korean youth becoming entrepreneurs. It will, however, offer more career choices for Korean youth, which we have already found to be significantly lacking. We all know that we learn from our mistakes so even if they fail, it will offer them more exposure and experiences; hence there should be more 
encouragement from the wider society and tangible endorsements to support them.

\section{Acknowledgments}

The previous version of this paper was presented at the 2021 Korea Business Association Conference and was selected for a best paper award at the conference.

\section{References}

Amiri, N. S., \& Marimaei, M. R. (2012). Concept of entrepreneurship and entrepreneurs traits and characteristics. Scholarly Journal of Business Administration, 2(7), 150-155.

Bosma, N., Hill, S., Ionescu-Somers, A., Kelley, D., Guerrero, M., \& Schott, T. (2021). 2020/2021 global report. Retrieved from https://www.gemconsortium.org/file/open?fileId=50691

Choi, M. (2011). A study on the influence of psychological home environment on entrepreneurial intention of college students (Master's thesis). Chung Ang University, Seoul, Korea.

Driessen, M. P., \& Zwart, P. S. (2017). The entrepreneur scan measuring characteristics and traits of entrepreneurs. Retrieved from http://entrepreneurscan.com/wp-content/uploads/2016/09/ E-Scan-MAB-Article-UK.pdf

Giacomin, O., Janssen, F., Pruett, M., Shinnar, R. S., Llopis, F., \& Toney, B. (2011). Entrepreneurial intentions, motivations and barriers: Differences among American, Asian and European students. International Entrepreneurship and Management Journal, 7(2), 219-238.

Guelich, U., \& Bosma, N. (2019, July 02). Youth entrepreneurship in Asia and the Pacific 2018-19. Retrieved from https://www. gemconsortium.org/report/50262

Han, J. H., \& Kim, J. H. (2013). A study on entrepreneurship education and entrepreneurial decision makings. Journal of Industrial Economics and Business, 26(6), 2777-2797.

Hayton, J. C., George, G., \& Zahra, S. A. (2002). National culture and entrepreneurship: A review of behavioral research. Entrepreneurship Theory and Practice, 26(4), 33-52.

Hofstede, G. (1985). The interaction between national and organizational value systems. Journal of Management Studies, 22(4), 347-357.

Hofstede, G., Hofstede, G. J., \& Minkov, M. (2010). Cultures and organizations: Software of the mind (3rd ed.). New York, NY: McGraw-Hill Education.

Hultberg, P. T., Calonge, D. S., \& Choi, T. (2021). Costs and benefits of private tutoring programs: The South Korean case. International Journal of Social Economics, 48(6), 862-877.

Hwang, H. (2020, October 19). 46.9\% of college students, career path 'undecided'. Daehak Newspaper. Retrieved from http:// www.dhnews.co.kr/news/articleView.html?idxno=129845

Jakubczak, J., \& Rakowska, A. (2014, June). Cultural values and entrepreneurship - Pilot study. Human capital without borders: Knowledge and learning for quality of life. Proceedings of the Management, Knowledge and Learning International Conference (pp. 529-536). Portorož, Slovenia.

Kerr, S. P., Kerr, W. R., \& Xu, T. (2017). Personality traits of entrepreneurs: A review of recent literature (Working Paper No. 24097). Retrieved from https://doi.org/10.3386/w24097

Kim, Y. (2021, April 22). News Focus: High youth unemployment continues during Moon's term. The Korea Herald. Retrieved from http://www.koreaherald.com/view.php?ud=20210422000380

Kong, H., \& Kim, H. (2018). The relationship between entrepreneurship education and entrepreneurship intention. The Journal of the Korean Business Administration, 31(12), 2223-2244.

Lee, S. W., \& Yang, D. W. (2020). A study on the influence of entrepreneurship education and TRIZ education on entrepreneurial intention: Focusing on the moderating effect of parental characteristics. Journal of Korea Technology Innovation Society, 23(5), 1011-1033.

Ministry of Education. (2020, December 28). Employment statistics for graduates of higher education institutions in 2019. Retrieved from https://moe.go.kr/boardCnts/view.do?boar$\mathrm{dID}=294 \&$ boardSeq $=83149 \& \mathrm{lev}=0 \&$ searchType $=$ null $\&$ sta tusYN=W\&page $=1 \& s=$ moe $\& \mathrm{~m}=020402 \&$ op Type $=\mathrm{N}$

Moon, J. Y. (2021, July 14). Why did a 20s female SKY university graduate become a wall-paper installer? [Interview]. Kyunghyang Newspaper. Retrieved from https://news.v.daum.net/v/kqQWwAKpTT

Oh, Y. M, \& Park, S. W. (2014). The effect of entrepreneurship education program on start-up intention. Korean Management Consulting Review, 14(2), 199-221.

Park, J. (2020, May 27). What are the criteria for choosing a job for college students. Retrieved from https://www.ulsan.ac.kr/ kor/CMS/Board/Board.do? mcode $=\& m$ Code $=$ MN104\&searchID=sch001\&searchKeyword=\%EC\%A7\%81\%EC\%97\%85\% EC\%84\%A0\%ED\%83\%9D\&mgr_seq=30\&mode=view\&mgr_ seq=30\&board_seq $=4625$

Prasongsukarn, K. (2009). Validating the cultural value scale (CVSCALE): A case study of Thailand. ABAC Journal, 29(2), 1-13.

Yang, J. H. (2015). A study of the effect of entrepreneurial education on entrepreneurial motivation: Focused on mediating effect of entrepreneurship. Journal of the Korea Academia-Industrial Cooperation Society, 16(4), 2564-2572.

Yonhap News. (2021, March 30). Over half of single S. Koreans in 30s living with parents: Report. The Korea Herald. Retrieved from http://www.koreaherald.com/view.php?ud=20210330000842

Yoo, B., Donthu, N., \& Lenartowicz, T. (2011). Measuring Hofst- 
ede's five dimensions of cultural values at the individual level: Development and validation of CVSCALE. Journal of International Consumer Marketing, 23(3-4), 193-210.
Yoon, J. (2021, December 11). The Korean education system needs to focus on entrepreneurship. Seoulz. Retrieved from https://seoulz.com/ the-korean-education-system-needs-to-focus-on-entrepreneurship/ 